\title{
Correlation Between Follicle Stimulating Hormone, Anti-Müllerian Hormone and Antral Follicle Count with Different Age Groups in Infertile Women
}

\author{
Juthi Bhowmik ${ }^{1 *}$ \\ Parveen Fatima ${ }^{2}$ \\ Jesmine Banu ${ }^{2}$ \\ Farzana Deeba ${ }^{2}$ \\ Sheuli Chowdhury ${ }^{3}$ \\ Shakeela Isharat ${ }^{2}$
}

\author{
'Department of Obstetrics \& Gynaecology \\ Mother \& Child Centre \\ Ashulia, Dhaka, Bangladesh.
}

${ }^{2}$ Department of Reproductive Endocrinology \& Infertility BSMMU, Dhaka, Bangladesh.

${ }^{3}$ Department of Obstetrics \& Gynaecology BSMMU, Dhaka, Bangladesh.

\footnotetext{
${ }^{*}$ Correspondence to:

Dr. Juthi Bhowmik

Consultant

Department of Obstetrics \& Gynaecology

Mother \& Child Centre

Ashulia, Dhaka, Bangladesh.

Mobile : +8801711354120

Email : bowmikjuthi1@gmail.com
}

Date of Submission : 11.09 .2020

Date of Acceptance : 10.01 .2021

www.banglajol.info/index.php/CMOSHMCJ

\begin{abstract}
Background: Reduced ovarian reserve predicts poor ovarian response and poor suc-cess rates in infertile women who undergo Assisted Reproductive Technology (ART). Ovarian reserve decreases with age but the rate of decline varies from one woman to another. Follicle Stimulating Hormone (FSH) Anti-Müllerian Hormone (AMH) and antral follicle count (AFC) represent the three most frequently utilized laboratory tests in determining Ovarian Reserve (OR). To determine correlation between FSH, $A M H$ and $A F C$ in infertile female.
\end{abstract}

Materials and methods: It was an observational (Cross sectional) study. This study was done in the Department of Reproductive Endocrinology and Infertility, Bangabandhu Sheikh Mujib Medical University (BSMMU), Dhaka, between July 2018 to June 2019. The study population consisted of all the diagnosed female infertility patients of reproductive age. The women attending the study center during study period having primary or secondary infertility was considered as study population. They were divided in 4 age groups 21-25, 26-30, 31-35 yrs and 36-40 yrs years. Data was collected using a structured questionnaire following physical \& lab examination. For $D_{2}$ FSH level fasting blood was collected on D2/3 of menstrual cycle, serum FSH level was measured by ADVIA Centraur ${ }^{(R)} X P$ immunoassay system. For $S$. AMH level blood sample was collected on $2^{\text {nd }}$ day of cycle and measured by BECKMAN COULTER machine using Chemiluminescent Immunoassay method. For AFC count TVS was done on $D_{2-5}$ of cycle using KONTRON medical USG machine. Collected data were classified, edited, coded and entered into the computer for statistical analysis by using SPSS version 23.

Results: Out of 74 patients the mean age was found $32.6 \pm 5.5$ years. Serum FSH, $A M H$ and AFC were significantly associated with different age group. A negative correlation was found between serum FSH and serum AMH in all age group. But strong correlation found in age group 31-35 yrs and in 36-40 years age group. A negative correlation was found between serum FSH and total AFC in age group 2630 years, 31-35 years and 36-40 years respectively. A positive correlation was found between serum AMH and total AFC in all age group but most strong in age group 31-35 years. In multivariate logistic regression analysis serum $A M H(<1.0 \mathrm{ng} / \mathrm{ml})$ and total AFC ( $<5$ number) were found to be significantly associated with age group $>35$ years patients.

Conclusion: In all age grqoup, FSH, AMH and AFC correlates but it is more pronounced in advanced age that means $>35$ years age group.

Key words: Follicle stimulating hormone; AntiMullerian Hormone; Antral follicle count.

\section{INTRODUCTION}

The term "ovarian reserve" has traditionally been used to describe a woman's reproductive potential, specifically the number and quality of oocytes she possesses ${ }^{1}$. 
A woman is born with about 2 million primordial follicles, yet by the onset of menarche only about 400,000 follicles are left due to natural follicular atresia. As a woman reaches her mid$30 \mathrm{~s}$, the pace of oocyte depletion begins to increase and by the time she reaches her late $30 \mathrm{~s}$, the number of follicles declines to approximately 25,000 , concomitant with a significant increase in miscarriage rate ${ }^{2}$.

Ovarian reserve is a complex clinical phenomenon influenced by age, genetics, and environmental variables. ${ }^{2}$ The decline in a woman's ovarian reserve with time is irreversible and the rate at which women lose primordial follicles varies considerably, with wide variation regarding the onset of sterility and timing of the menopausal transition ${ }^{2}$.

Ovarian reserve tests started to emerge during the rise of ART in the late 1980 s to predict both responsiveness to super ovulation drugs and the odds of pregnancy with treatment. They include both biochemical basal and provocative tests and ultrasound imaging of the ovaries. The first test to be introduced was day-3 follicle-stimulating hormone (FSH) (1988), followed by Clomiphene Citrate Challenge Test (CCCT) (1989) Gonadotropin Releasing-Hormone (GnRH) agonist (1989) inhibin B (1997) Antral Follicular Count (AFC) (1997) and Anti Müllerian Hormone $(\mathrm{AMH})^{2}$.

Early follicular phase (Basal) FSH as a marker of ovarian reserve was proposed almost 30 years ago, as a tool to predict ovarian response to In Vitro Fertilization (IVF) ${ }^{3}$. This test is an indirect assessment of ovarian reserve and is based on the feedback inhibition of FSH pituitary secretion by ovarian factors.

Women with normal ovarian reserve have sufficient production of ovarian hormones at this early stage of the menstrual cycle to maintain FSH levels within normal range ${ }^{2}$.

However, basal FSH testing has several major limitations including significant intercycle and intracycle variability that limits its reliability ${ }^{4}$. it requires a functional hypothalamus-pituitary-ovarian axis, and it is not adequately sensitive for clinical utility-only elevations carrying significance ${ }^{5}$.

A single abnormal FSH value in a woman $<40$ years of age may not predict a poor response to stimulation or failure to achieve pregnancy and should prompt repeat testing ${ }^{6}$.

The ovary begins producing AMH in utero at about 36 weeks of gestation ${ }^{7}$. Its levels rise in young women beginning in adolescence and peak at about 25 years of age, then gradually decline until reaching undetectable levels a few years prior to menopause. Since AMH is expressed during normal early folliculogenesis (Secreted by early follicles up to $6 \mathrm{~mm}$ ), it is relatively independent of gonadotropins circulating at physiologic levels and allows for testing anytime throughout the cycle ${ }^{2}$.

$\mathrm{AFC}$ is the sum of follicles in both ovaries as observed on ultrasound in the early follicular phase (Day 2-4) of the menstrual cycle. Antral follicles are defined as those measuring 2-10 mm in largest mean diameter on 2-dimensional plane. AFC is easy to carry out, provides an immediate result and has good intercycle reliability and good interobserver reliability when measured in experienced centers using a minimal number of sonographers. Its precision is compromised with overweight and obese individuals or when using multiple sonographers ${ }^{8}$.

\section{MATERIALS AND METHODS}

It was an observational (Cross sectional) study. This study was done in the Department of Reproductive Endocrinology and Infertility, Bangabandhu Sheikh Mujib Medical University (BSMMU) Dhaka, between July 2018 to June 2019. The study population consisted of all the diagnosed female infertility patients of reproductive age. The women attending the study center during study period having primary or secondary infertility was considered as study population. They were divided in 4 groups, 21-25, 26-30, 31-35, 36-40 years. Data was collected using a structured questionnaire following physical \& lab examination. For $\mathrm{D}_{2}$ FSH level fasting blood was collected on D2/3 of menstrual cycle, serum FSH level was measured by ADVIA Centraur ${ }^{(\mathrm{R})}$ XP immunoassay system. For S. AMH level blood sample was collected on any day of cycle and measured by BECKMAN COULTER machine using Chemiluminescent Immunoassay method. Statistical analysis was carried out by using the Statistical Package for Social Sciences version 16.0 for Windows (SPSS Inc Chicago, Illinois, USA). The mean values were calculated by frequencies and percentages. The quantitative observations were indicated by frequencies and percentages. Chi square test was used for categorical variables. Unpaired t-test was used for continuous variables. Pearson's correlation coefficient was used to test the relationship between the groups. Multivariate logistic regression analysis was used for risk factors of infertile women. P values $<0.05$ was considered as statistically significant.

\section{RESULTS}

A total of 74 infertile women's were included in this study with maintaining inclusion \& exclusion criteria. They were divided in 4 age groups- $21-25$ years, 26-30 years, $31-35$ years and 3640 years.

Table I : Distribution of the study patients by age $(n=74)$.

\begin{tabular}{lcc} 
Age (Years) & Number of patients & Percentage \\
$21-25$ & 6 & 8.1 \\
$26-30$ & 23 & 31.1 \\
$31-35$ & 18 & 24.3 \\
$36-40$ & 27 & 36.5 \\
Mean \pm SD & \multicolumn{2}{c}{$32.6 \pm 5.5$} \\
Range (Min-max) & \multicolumn{2}{c}{$22.0-40.0$} \\
\hline
\end{tabular}

Table II : Distribution of the study patients according to serum $\mathrm{FSH}(\mathrm{n}=74)$.

\begin{tabular}{|c|c|c|c|c|c|c|c|c|c|}
\hline Serum FSH (IU/L) & & $\begin{array}{l}21-25 \\
\text { years } \\
(n=6)\end{array}$ & & $\begin{array}{r}\text { 26-30 } \\
\text { years } \\
(n=23)\end{array}$ & & $\begin{array}{c}31-35 \\
\text { years } \\
(\mathrm{n}=18)\end{array}$ & ( & $\begin{array}{c}36-40 \\
\text { years } \\
(n=27)\end{array}$ & p value \\
\hline & $\mathrm{n}$ & $\%$ & n & $\%$ & n & $\%$ & n & $\%$ & \\
\hline 10.0 (Normal) & 6 & 100.0 & 22 & 95.7 & 9 & 50.0 & 12 & 44.4 & \\
\hline$>10.0$ (Abnormal) & 0 & 0.0 & 1 & 4.3 & 9 & 50.0 & 15 & 55.6 & \\
\hline $\operatorname{Mean} \pm \mathrm{SD}$ & 5.2 & \pm 1.1 & 6.4 & \pm 2.5 & 10.7 & \pm 6.1 & 10.2 & \pm 3.1 & $0.001^{\mathrm{s}}$ \\
\hline Range (min-max) & 4.0 & -7.2 & 3.02 & -15.9 & 4.0 & -27.0 & & -16.0 & \\
\hline
\end{tabular}

$s=$ significant, $p$ value reached from ANOVA test. 
Table III : Distribution of the study patients according to serum $\mathrm{AMH}(\mathrm{n}=74)$.

\begin{tabular}{|c|c|c|c|c|c|c|c|c|c|}
\hline \multicolumn{3}{|c|}{$\begin{array}{r}\text { Serum AMH (ng/ml) Age 21-25 } \\
\text { years }(n=6)\end{array}$} & \multicolumn{2}{|c|}{$\begin{array}{c}\text { Age } 26-30 \\
\text { years }(n=23)\end{array}$} & \multicolumn{2}{|c|}{$\begin{array}{c}\text { Age } 31-35 \\
\text { years }(n=18)\end{array}$} & \multicolumn{2}{|c|}{$\begin{array}{c}\text { Age } 36-40 \\
\text { years }(n=27)\end{array}$} & \multirow[t]{2}{*}{ p value } \\
\hline & n & $\%$ & n & $\%$ & n & $\%$ & $\mathrm{n}$ & $\%$ & \\
\hline$<1.0$ (Low) & 0 & 0.0 & 1 & 4.3 & 5 & 27.8 & 13 & 48.1 & \\
\hline 1.0-3.5 (Normal) & 6 & 100.0 & 22 & 95.7 & 13 & 72.2 & 14 & 51.9 & \\
\hline Mean $\pm S D$ & 2.87 & \pm 0.80 & 2.44 & \pm 0.77 & 1.77 & \pm 1.10 & 1.37 & \pm 1.06 & $0.001^{\mathrm{s}}$ \\
\hline Range (min-max) & 1.50 & -3.50 & 0.46 & -3.50 & 0.18 & -3.30 & 0.02 & -3.48 & \\
\hline
\end{tabular}

$s=$ significant, $p$ value reached from ANOVA test.

Table IV : Distribution of the study patients according to total $\operatorname{AFC}(n=74)$.

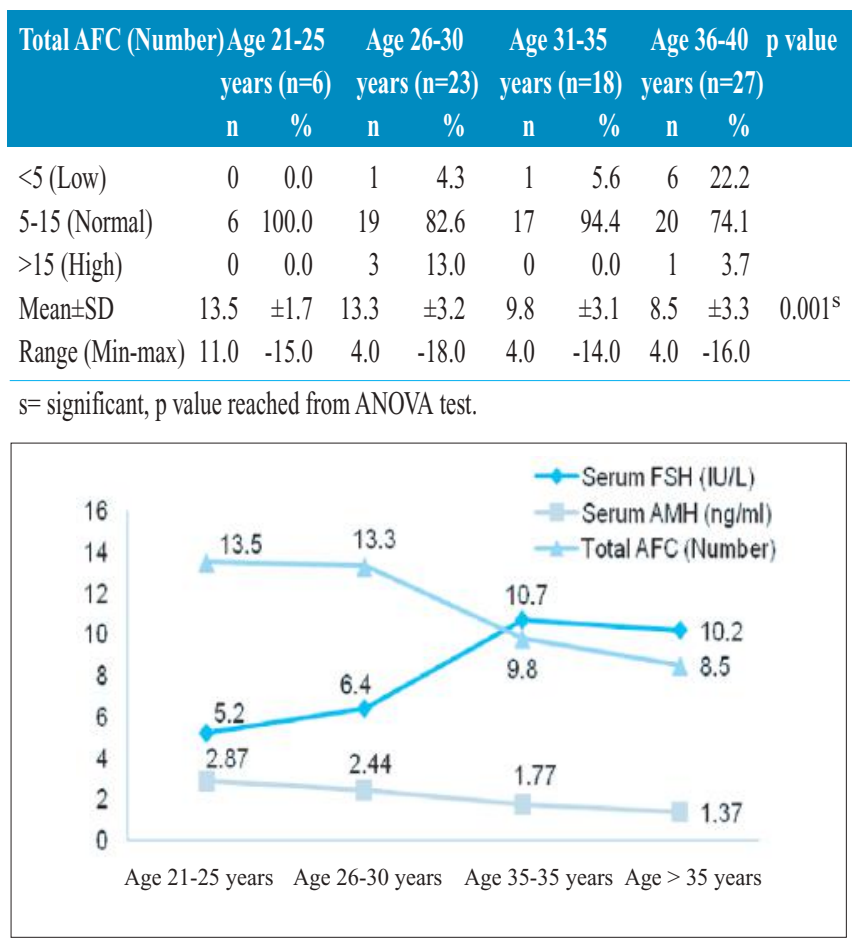

Figure 1 : Line diagram showing mean serum FSH, serum $\mathrm{AMH}$ and total AFC in different age years.

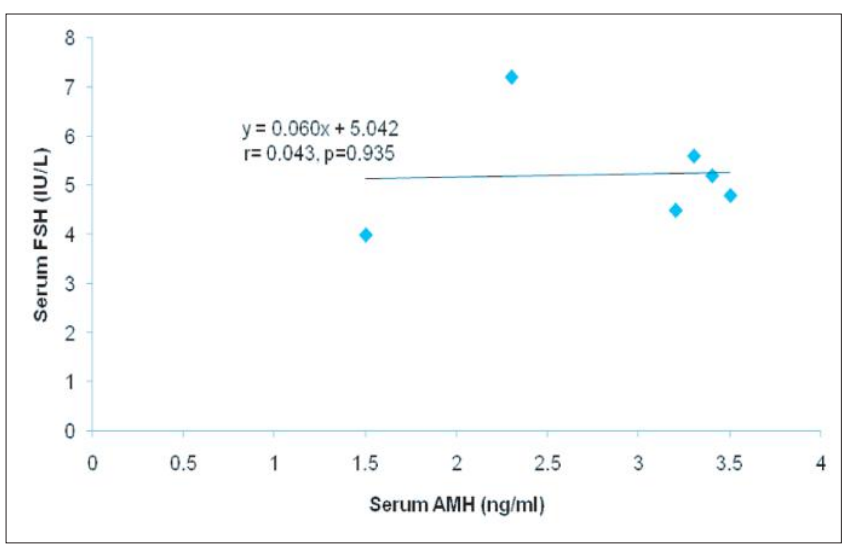

Figure 2 : The scatter diagram showing no correlation $(\mathrm{r}=$ $0.043, \mathrm{p}=0.935$ ) between serum FSH and serum AMH in age group 21-25 years.

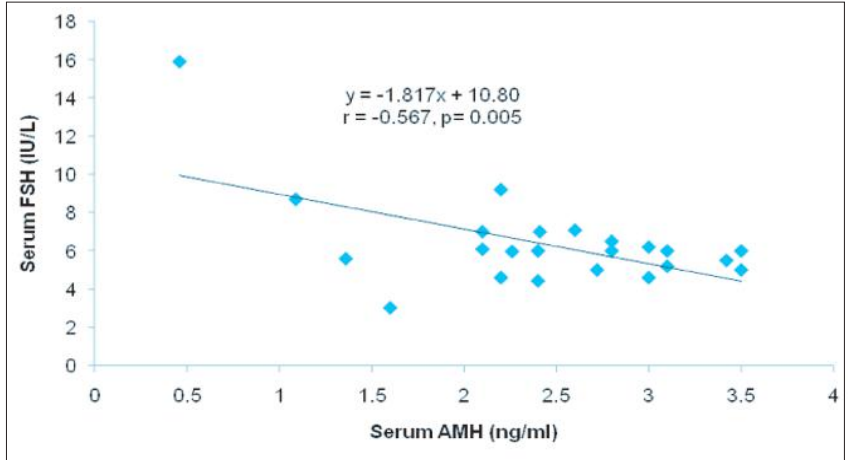

Figure 3 : The scatter diagram showing negative correlation $(r=-0.567, p=0.005)$ between serum FSH and serum AMH in age group 26-30 years.

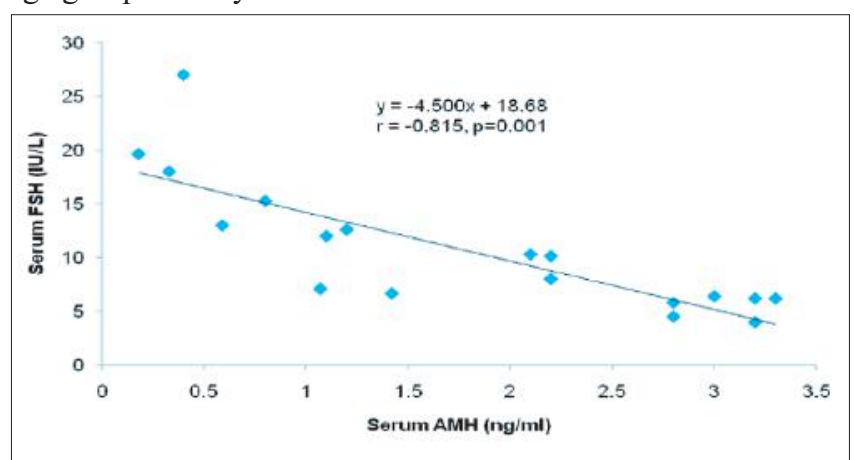

Figure 4 : The scatter diagram showing negative correlation $(\mathrm{r}=-0.815, \mathrm{p}=0.001)$ between serum FSH and serum AMH in age group 31-35 years.

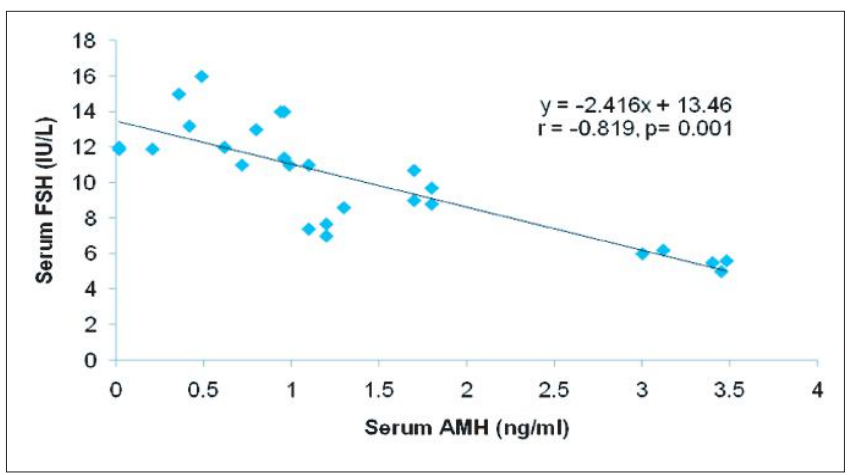

Figure 5 : The scatter diagram showing negative correlation $(\mathrm{r}=-0.819, \mathrm{p}=0.001)$ between serum FSH and serum AMH in age group 36-40 years.

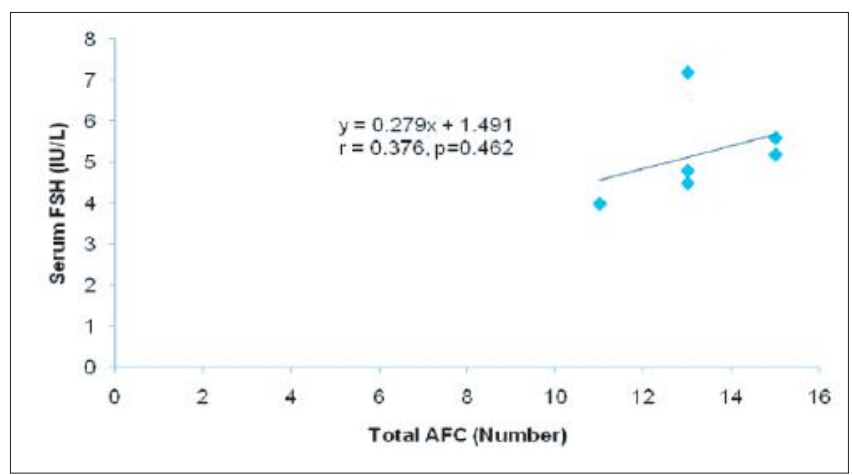

Figure 6 : The scatter diagram showing positive correlation ( $\mathrm{r}=$ $0.376, \mathrm{p}=0.462$ ) between serum FSH and total AFC in age group 21-25 years. 


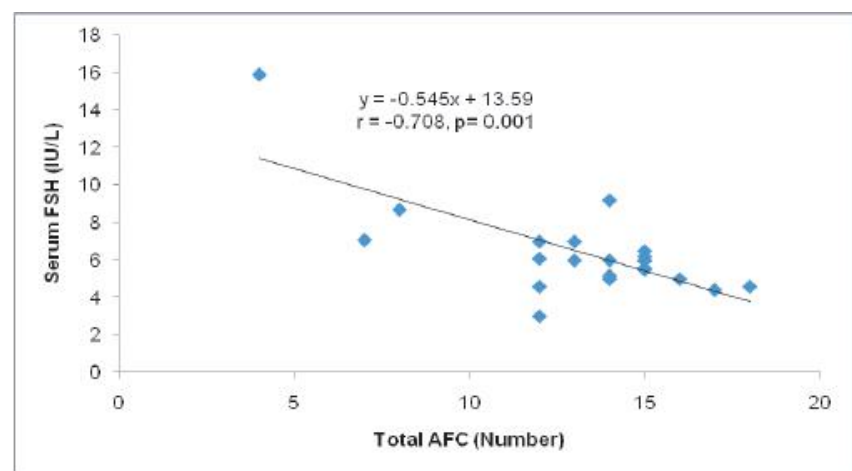

Figure 7 : The scatter diagram showing negative correlation $(r=-0.708, p=0.001)$ between serum FSH and total AFC in age group 26-30 years.

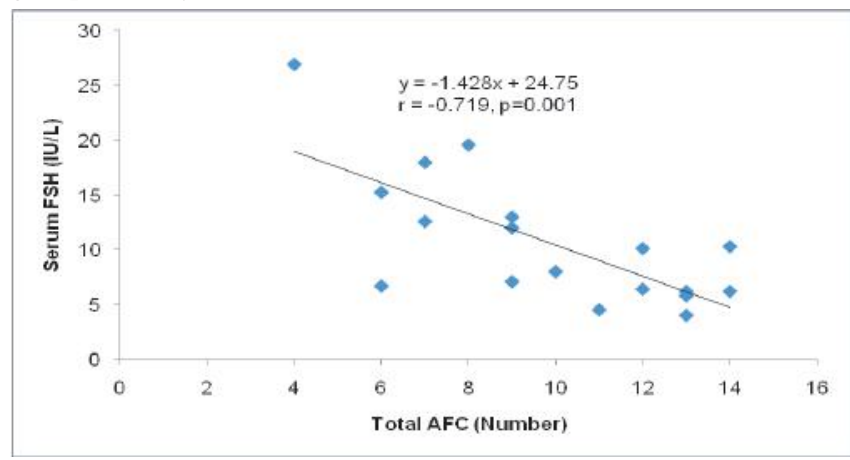

Figure 8 : The scatter diagram showing negative correlation $(r=-0.719, p=0.001)$ between serum FSH and total AFC in age group 31-35 years.

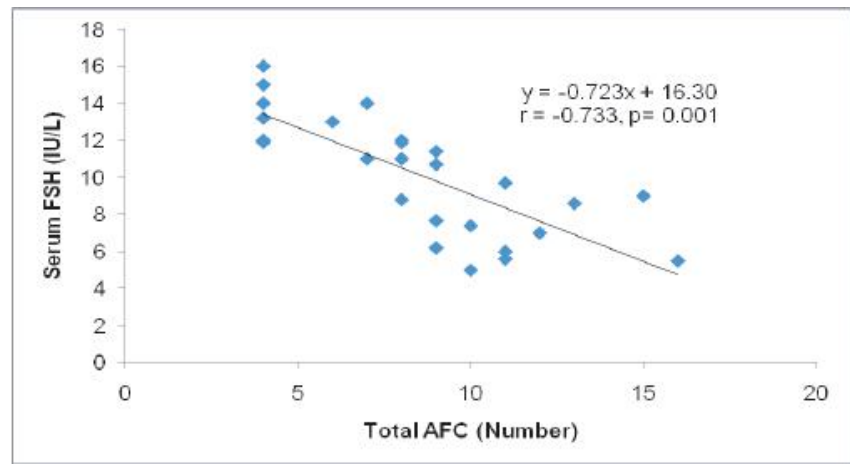

Figure 9 : The scatter diagram showing negative correlation $(\mathrm{r}=-0.733, \mathrm{p}=0.001)$ between serum FSH and total AFC in age group 36-40 years.

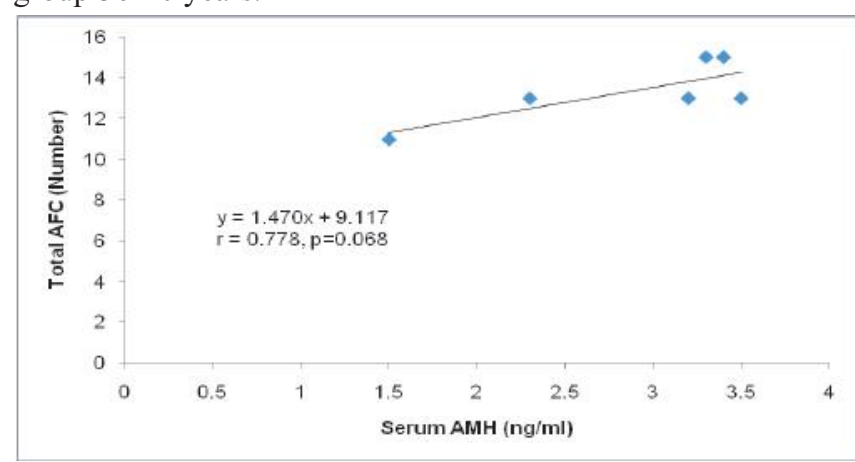

Figure 10 : The scatter diagram showing positive correlation $(\mathrm{r}=0.778, \mathrm{p}=0.068)$ between serum $\mathrm{AMH}$ and total $\mathrm{AFC}$ in age group 21-25 years.

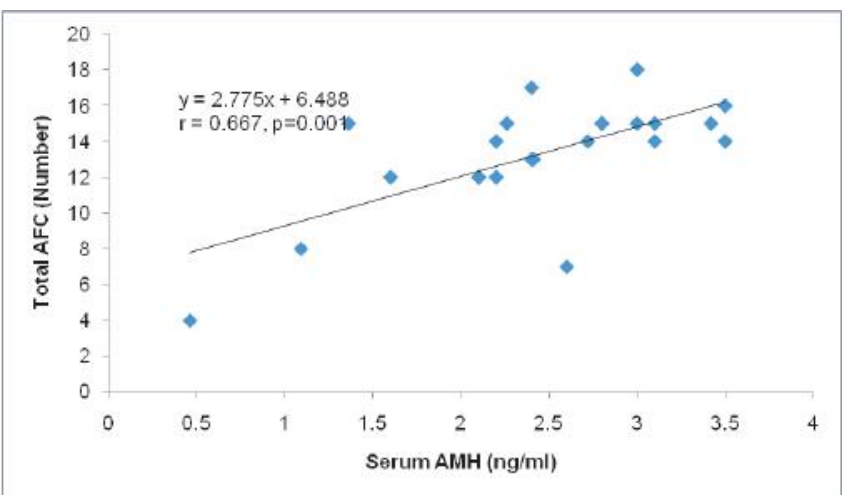

Figure 11 : The scatter diagram showing positive correlation $(\mathrm{r}=0.667, \mathrm{p}=0.001)$ between serum $\mathrm{AMH}$ and total $\mathrm{AFC}$ in age group 26-30 years.

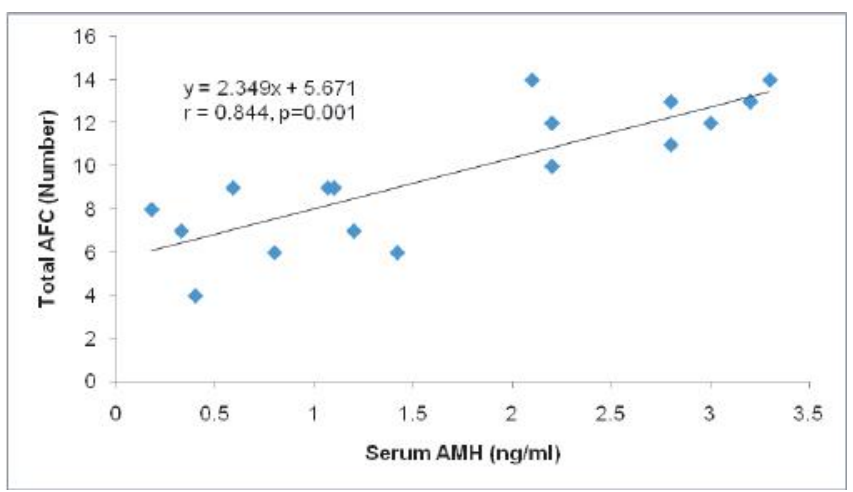

Figure 12 : The scatter diagram showing positive correlation $(r=0.844, p=0.001)$ between serum AMH and total AFC in age group 31-35 years.

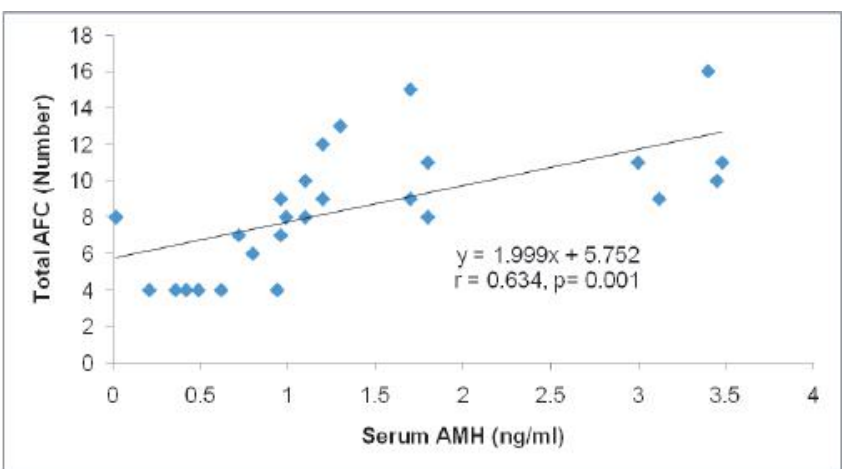

Figure 13 : The scatter diagram showing positive correlation $(r=0.634, p=0.001)$ between serum AMH and total AFC in age group 36-40 years.

Table V : Multi variable logistic regression analysis for age $>35$ years.

\begin{tabular}{lccrc} 
Risk factors & $\begin{array}{c}\text { Regression } \\
\text { coefficient }(\beta)\end{array}$ & $\begin{array}{c}\text { Odds Ratio } \\
(\text { OR) }\end{array}$ & $\begin{array}{c}\text { 95\% CI for } \\
\text { OR }\end{array}$ & P value \\
Serum FSH $(>10.0 \mathrm{IU} / \mathrm{L})$ & 0.934 & 2.544 & $0.901-7.182$ & $0.078^{\mathrm{ns}}$ \\
Serum AMH $(<1.0 \mathrm{ng} / \mathrm{ml})$ & 1.531 & 4.626 & $1.649-12.976$ & $0.004^{\mathrm{s}}$ \\
Total AFC $(<5$ number $)$ & 2.242 & 9.412 & $2.543-34.838$ & $0.001^{\mathrm{s}}$ \\
\hline
\end{tabular}

$\mathrm{s}=$ significant, $\mathrm{ns}=$ significant, $\mathrm{p}$-value reached from multivariate analysis by binary logistic regression analysis 


\section{DISCUSSION}

In present study it was observed that all (100\%) patients have normal ( $10 \mathrm{IU} / \mathrm{L}$ ) serum FSH in age group 21-25 years, 95.7\% in $26-30 \mathrm{yrs}, 50 \%$ in $31-35 \mathrm{yrs}$ and $44.4 \%$ in age group $36-40$ yrs. The mean difference was statistically significant $(\mathrm{p}<.05)$ among four group. Barbakadze et al found significant association between serum FSH with different age group. They divided their subject into 3 age groups, $<35 \mathrm{yr}, 35-40 \mathrm{yrs}$ and 41-46 yrs. In their study serum FSH level showed a significantly higher result only in age group 41-46 yrs compared to age group $<35$ yrs $^{9}$.

Ozcan et al revealed that the AMH concentration declined sig-nificantly with increasing age. This decline began at the age of 30 , and it became dramatically evident from the age of 35 . This suggests that some women may be candidates of poor response due to the unexpected risk of a diminishing ovarian reserve after age $30^{10}$. In this study $100 \%$ patient were found normal (1.0-3.5 ng/ml) serum AMH in age group 21-25 yrs, 95.7\% in $26-30$ yrs, $72.2 \%$ in $31-35$ yrs and $51.9 \%$ in age group $36-40$ yrs. The mean serum AMH was found $2.87 \pm .8 \mathrm{ng} / \mathrm{ml}$ in age group 21-25 yrs, $2.44 \pm .77 \mathrm{ng} / \mathrm{ml}$ in age group 26-30 yrs, $1.77 \pm 1.1$ $\mathrm{ng} / \mathrm{ml}$ in age group 31-35 yrs and $1.37 \pm 1.06 \mathrm{ng} / \mathrm{ml}$ in $36-40$ yrs. The mean difference was statistically significant $(\mathrm{p}<0.05)$ among 4 groups.

In the largest study analyzing age-specific medians for serum AMH by Seifer et al reported that both median and mean AMH values were inversely associated with age ${ }^{11}$. The average yearly decrease in the median serum AMH value was $0.2 \mathrm{ng} / \mathrm{ml} /$ year upto age 35 then diminished to $0.1 \mathrm{ng} / \mathrm{mL} /$ year after the age of 35 . The most striking study on means of AMH in general population is the study of Tremellen and Kolo ${ }^{12}$. They evaluated a total of 1032 women aged between 18 and 43 years and found that the mean serum AMH level is relatively stable at approximately (4.1 $\mathrm{ng} / \mathrm{ml}$ ) (1 $\mathrm{ng} \mathrm{AMH}$ is $7.143 \mathrm{pmol}$ ) in the under 30-year-old range, however, from 30 years of age onwards the serum AMH levels decline rapidly, became half in concentration to an average of only $(1.95 \mathrm{ng} / \mathrm{ml})$ in the 35-39 year old age group.

Barbakadze et al found significant negative correlation of serum AMH with advancing age group 9 . A study by Nelson et al with 9601 infertile women showed that serum AMH will decrease with age and found that serum $\mathrm{AMH}$ in all percentiles were lower compared to the study. This difference might be caused by several factors, including different populations with different genetic and environmental backgrounds, which could lead to a different ovarian biological age compared to chronological age.

In current study $100 \%$ patients were found normal (5-15 numbers) total AFC in age group 21-25 yrs, $82.6 \%$ in $26-30 \mathrm{yrs}$, $94.4 \%$ in $31-35$ yrs and $74.1 \%$ in age group $36-40$ yrs. The mean AFC was found $13.5 \pm 1.7$ in $21-25 \mathrm{yrs}, 13.3 \pm 2$ in $26-30$ yrs, $9.8 \pm 3.1$ in $31-35$ yrs and $8.5 \pm 3.3$ in $36-40$ yrs group. The mean difference was significant among 4 groups $(\mathrm{p}<0.05$ ).

In this study it was observed that there was a moderate negative correlation $(\mathrm{r}=-0.567, \mathrm{p}=.005)$ between serum FSH and serum $\mathrm{AMH}$ in age group 26-30 yrs. But strong negative correlation $(\mathrm{r}=-0.815, \mathrm{p}=0.001)$ in $31-35 \mathrm{yrs}$ and $(\mathrm{r}=-0.819, \mathrm{p}=0.001)$ in $36-40$ yrs age group. Barbakadze et al consisted that $\mathrm{AMH}$ showed a negative correlation with FSH $(\mathrm{rs}=-0.48, \mathrm{p}<0.0001)^{9}$. Gada et al found that there was a negative correlation between $\mathrm{AMH}$ and FSH $(\mathrm{R}=-0.41)^{13}$. Okunola et al showed in their study the Pearson's coefficient for the correlation between FSH and AMH after controlling for age was $-0.311(\mathrm{p}=0.012)^{14}$. Scheffer et al documented that AMH was significantly correlated with FSH $(\mathrm{r}=-0.32, \mathrm{p}<.01)^{15}$.

Gleicher et al reported that women with normal AMH and FSH produced high number of oocytes, whereas women with normal FSH but decreasing AMH produced a significantly lower number of oocytes ${ }^{16}$. This also indicates that serum AMH levels are more important predictors of ovarian aging than FSH levels. This is similar with previous studies by Barad et al that shows that $\mathrm{AMH}$ levels are better predictors of response to ovarian stimulation and clinical pregnancy than baseline $\mathrm{FSH}^{17}$. The relatively lower slopes of increasing FSH in older age have made FSH a late predictor of ovarian reserves ${ }^{18}$.

In this study there was a negative correlation between FSH and AFC in age group 26-30 yrs $(r=-0.708, \mathrm{p}=0.001) 31-35 \mathrm{yrs}(\mathrm{r}=$ $-0.719, \mathrm{p}=0.001)$ and $36-40 \mathrm{yrs}(\mathrm{r}=-0.733, \mathrm{p}=0.001)$. Barbakadze et al showed significant negative correlation between FSH and AFC only in age group $>40$ yrs. $(r=-0.42, p=0.001)^{9}$. In this current study there was a positive correlation between serum $\mathrm{AMH}$ and $\mathrm{AFC}$ in all age group. But it is most strong in age group 31-35 yrs group $(r=0.844, p=0.001)$. Barbakadze et al showed in their study AMH and AFC level had positive association for group I $(\mathrm{r}=0.57, \mathrm{P}<0.001)$ group II $(\mathrm{r}=0.69, \mathrm{p}<0.001)$ and group III ( $r=0.47, p<0.002)$ which were significant ${ }^{9}$.

Scheffer et al reported that AMH was significantly correlated with AFC $(\mathrm{r}=0.81, \mathrm{p}<.00001)^{15}$. Gada et al showed that there was a strong correlation between AMH and AFC (Correlation coefficient, $\mathrm{R}=0.72)^{13}$.

Barbakadze et al reported that according to regression analysis, age only explained the variation of $\mathrm{AMH}$ in $22 \%$, the variation of FSH in $14 \%$ and the variation of AFC in $27 \%$ of changes ${ }^{9}$. Tehraninezhad et al showed that among AFC and age, AFC was the independent predictor (beta $=0.6, p=0.001)^{19}$. Among FSH and age, age was the only independent predicting variable (beta $=-0.4$, $\mathrm{p}=0.001)$. In this study it was found that in multivariate logistic regression analysis, patients having serum AMH $(<1.0 \mathrm{ng} / \mathrm{ml})$ was 4.626 (95\% CI 1.649 to 12.976$)$ times in age group $>35$ years. Patients having total AFC ( $<5$ number) was 9.412 (95\% CI 2.543 to 34.838 ) times in age group $>35$ years. Serum AMH and total AFC were found to be significantly $(\mathrm{p}<0.05)$ associated with age group $>35$ years patients.

\section{CONCLUSION}

In all age group, $\mathrm{FSH}, \mathrm{AMH}$ and $\mathrm{AFC}$ correlates but it is more pronounced in advanced age that means $>35$ years age group. Further studies can be undertaken by including large number of patients.

\section{DISCLOSURE}

All the authors declared no competing interest. 


\section{REFERENCES}

1. Practice Committee of the American Society for Reproductive Medicine. Testing and interpreting measures of ovarian reserve: A committee opinion. Fertil Steril. 2015;103:9-17.

2. Tal R and Seifer DB. Ovarian reserve testing: A user's guide. American Journal of Obstetrics Gynaecology. 2017; 217(2): 129-140.

3. Sharara FI, Scott RT Jr and Seifer DB. The detection of diminished ovarian reserve in infertile women. Am J Obstet Gynecol. 1998;179:804-812.

4. Toner JP, Philput CB, Jones GS and Muasher SJ. Basal follicle-stimulating hormone level is a better predictor of in vitro fertilization performance than age. Fertil Steril. 1991;55(4):784-791.

5. Kwee J, Schats R, McDonnell J, Lambalk CB and Schoemaker J. Intercycle variability of ovarian reserve tests: results of a prospective randomized study. Hum Reprod. 2004;19:590-595.

6. Roberts JE, Spandorfer S, Fasouliotis SJ, Kashyap S and Rosenwaks Z. Taking a basal follicle-stimulating hormone history is essential before initiating in vitro fertilization. Fertil Steril. 2005;83(1):37-41.

7. Rajpert-De Meyts E, Jorgensen N, Graem N, Muller J, Cate RL and Skakkebaek NE. Expression of anti-mullerian hormone during normal and pathological gonadal development: association with differentiation of Sertoli and granulosa cells. J Clin Endocrinol Metab. 1999;84(10):3836-3844

8. Broer SL, Mol BW, Hendriks D and Broekmans FJ. The role of antimüllerian hormone in prediction of outcome after IVF: comparison with the antral follicle count. Fertil Steril. 2009;91: 705-714

9. Barbakadze L, Kristesashvili J, Khonelidze N and Tsagareishvili G. The Correlations of Anti-Mullerian Hormone, Follicle-Stimulating Hormone and Antral Follicle Count in Different Age Groups of Infertile Women', International Journal of Fertility and Sterility. 2015;8(4):393-398

10. Ozcan P, Ficicioglu C, Yesiladali M, Devranoglu B, Ayd n S and Batmaz G. Age-Related Distribution of Basal Anti-Mullerian Hormone Levels in a Population of Infertile Women. J Clin Anal Med. 2016; 7(3): 355-358

11. Seifer DB, Baker VL and Leader B. Age-specific serum anti-Müllerian hormone values for 17,120 women presenting to fertility centers within the United States. Fertil Steril. 2011;95(2): 747-750.

12. Tremellen K and Kolo M. Serum anti-Mullerian hormone is a useful measure of quantitative ovarian reserve but does not predict the chances of live-birth pregnancy. Aust N Z J Obstet Gynaecol. 2010;50(6): 568-572.

13. Gada R, Morbeck D, Amols M, Rollene N, Jensen J, Coddington C and Rochester MN. Anti-mullerian hormone (AMH), antral follicle count (AFC) and age predict IVF outcomes significantly better than follicle timulating hormone. Fertility and Sterility. 2010;94(4): S97.

14. Okunola T, Ajenifuja K, Loto O, Salawu A and Omitinde S.Follicle stimulating hormone and anti-müllerian hormone among fertile and infertile women in Ile-Ife, Nigeria: is there a difference?', Int J Fertil Steril. 2017;11(1):33-39.

15. Scheffer JAB, Scheffer B, Scheffer R, Florencio F, Grynberg M and Lozano DM. Are age and anti-Müllerian hormone good predictors of ovarian reserve and response in women undergoing IVF?. JBRA Assisted Reproduction. 2018;22(3): 215-220.

16. Gleicher N, Weghofer A and Barad DH. Discordance between follicle stimulating hormone (FSH) an anti mullerian hormone (AMH) in female infertility', Reprod Biol Endocrinol. 2010; 8(64): 1-7.

17. Barad DH, Weghofer A and Gleicher N. Comparing anti-Mullerian hormone (AMH) and follicle-stimulating hormone (FSH) as predictors of ovarian function. Fertil Steril. 2010;91(4): 1553-1555

18. Knauff EAH, EijkmansMJC, Lambalk CB, Kate-BooijMJ, Hoek A. Anti Mullerian Hormone, Inhibin B, and Antral Follicle Count in young woman with ovarian failure', J Clin Endocrinol Metab 2009;94(3):786-792.

19. Tehraninezhad ES, Mehrabi F, Taati R, Kalantar V, Aziminekoo E and Tarafdari A. Analysis of ovarian reserve markers (AMH, FSH, AFC) in different age strata in IVF/ICSI patients. Int J Reprod BioMed. 2016;14(8): 501-506. 